\title{
Quantifying the Parameters Influencing Heat Transfer during Quenching Of Metal Plate
}

\author{
Gaurav A. Kulkarni, E. Specht \\ Institute of Fluid Dynamics and Thermodynamics, Otto-von-Guericke University \\ Magdeburg, 39106, Germany \\ gaurav.kulkarni@ovgu.de
}

\begin{abstract}
The process of quenching with an array of jets, to improve properties of metal, is a widely used application in metal casting and metal processing industries. This paper reviews the quenching of a metal sheet with series of jets from a mold under static mold and moving mold conditions. Experiments were conducted on various samples under different parameters and the temperature on the back side of the plate was measured using an infrared camera with high local resolution. An analysis method developed by the author was used to obtain heat flux as a function of temperature on the quenching side of the sheet in the steady state region, accounting for the thickness of the sheet. It is observed that the analysis method is also less sensitive to experimental and numerical errors. The thermal history data is used in conjuncture with the analysis method in order to obtain the heat flux and surface temperatures. A study analysing the boiling curve and width of the wetting front is conducted for different parameters like metal, moving speed, jet velocity, water temperature and initial temperature. The results are compared and analysed for identifying various influencing parameters during the quenching process.
\end{abstract}

Keywords: Heat Transfer Analysis, Quenching, DC Casting, Boiling Curve.

\section{Motivation}

Obtaining the boiling curve is a fundamental requirement for simulation of quenching or metal processing as it determines the rate of cooling. A high cooling rate, would lead to better metallurgical properties but induces residual stresses, which deteriorates the mechanical properties. Hence, obtaining an optimum cooling strategy is important to get the balance between properties. The boiling curve is sensitive to the experimental setup. Hence analysis is conducted on a setup similar to that in industry. Experiments with relative motion between plate and mold were conducted like in continuous or semicontinuous casting process or in quenching of long profiles. Also, experiments were conducted in a setup where there is no relative motion between hot metal sheet and the mold like in batch quenching. In this study, boiling curve along with width of various wetting fronts are analysed for various casting speeds, metals and initial temperatures.

\section{Introduction}

Quenching with an array of jets is a widely used application in metal casting and in the metal processing industry. During this process, the metal experiences highly non-uniform thermal gradients, which results in thermal stresses and distortions or other forms of defects. Hence quantifying the heat transfer to cooling water is very important for optimization of quenching process. Heat transfer to the cooling water is particularlycomplicated, due to the phase changing nature of water, typically resulting in the heat extraction rate varying from those associated with transition or film boiling through nucleate boiling to convection.

Large number of researchers have studied the quenching of hot metal sheet. Elias and Yadigaroglu (1977) [1] developed an analytical one-dimensional model for the rewetting of a hot plate and predicted the wetting front velocity. They focussed the importance of axial heat conduction. Wells and Cockcroft (2001) [2] applied an iterative two-dimensional FE inverse heat conduction model to estimate the surface heat flux. The experimental data obtained from thermocouples was smoothed and subsequently used for the inverse model. Nallathambi and Specht (2009) [3] applied a non-iterative finite element method for a two-dimensional inverse heat conduction problem, but it was observed that inverse FE model is very sensitive to experimental and numerical errors causing fluctuations in the results. 
Mozumder et al. (2005) [4] studied the delay of wetting front propagation during jet impingement quenching and concluded that the value of maximum heat flux is 5 - 60 times higher than the heat transfer value just before the wetting front movement. Akmal et al. (2008) [5] studied the influence of initial surface temperature, water temperature and jet velocity on curved surface exposed to an impinging water jet.

Bakken and Bergstrm (1986) [6] conducted heat transfer ,measurements during CD casting of aluminium alloy, with help of thermocouples for various casting speeds over a range of $1 \mathrm{~mm} / \mathrm{s}$ to $2.5 \mathrm{~mm} / \mathrm{s}$. Opstelten and Rabenberg (1999) [7] conducted experimental analysis along with an inverse model to obtain the boiling curve under moving mold condition. The authors have studied the influence of various parameters like water flow rate, casting speed and the kind of alloy. Hnizdil et al. (2014)[8] studied the influence of impact angle and pressure on a vertically moving hot steel sheet with sprays.

Beck et al. 1985 [9] used inverse heat conduction technique for estimating heat flux on the surface of a conduction medium through the use of temperature measurements from experiments. Ijaz et al. (2007) [10] have presented an adaptive state estimator for the estimation of input heat flux and measurement sensor bias in a two-dimensional inverse heat conduction problem. Continuous-time analogue hop-field neural network based inverse solution algorithm has been proposed by Hwang (2006) [11] and Deng (2006) [12] and. Gradeck et al. (2011) [13] used temperature data from infrared camera to obtain transient heat flux with an inverse heat conduction problem formulated using an analytical solution of the direct problem expressed in Hankel space.

This paper is primarily focusing on heat transfer during the steady-state region of quenching of hot metal sheet under moving mold and stationary mold conditions. Cooling because of diffusion is also incorporated as there will be temperature drop before heat transfer to quenching water. The interface temperature and heat flux as a function of position are determined based on 1-D model and 2-D finite difference model respectively, which is used to obtain the heat flux as a function of temperature on quenching side of the plate. In order to identify the parameters influencing the boiling curve, experiments were conducted on metal sheet with varying casting speeds, various metals and metal sheets with different initial temperatures and the data was analysed to obtain heat flux as a function of temperature on quenching side of the sheet.

\section{Experimental Method}

\subsection{Setup}

An experimental setup, consisting of a mold with an array of jets that creates a water curtain along the surface of metal is used. The dimension of the mold used are $120 \mathrm{~mm}$ x $120 \mathrm{~mm}$ x $90 \mathrm{~mm}$. It has 11 small orifices at the base, each of $2 \mathrm{~mm}$ in diameter. The experimental setup of this moving mold and stationary mold analysis is shown in Fig. 1. A metal plate is heated to the desired initial temperature and is shifted immediately to the quenching chamber. During the quenching process, an Infra-Red camera is used to capture and store the thermal images at a frame rate of 150 images per second with a resolution of 240 x 80 pixels. The samples were painted black on the measuring side in order to increase the emissivity, for more accurate measurements.

Table 1: Material Properties.

\begin{tabular}{|c|c|c|c|c|}
\hline & Aluminum & Nickel & Copper & Nicrofer \\
\hline Density $\left(\mathrm{kg} / \mathrm{m}^{3}\right)$ & 2700 & 8908 & 8940 & 8400 \\
\hline Thermal Conductivity $(\mathrm{W} / \mathrm{m} \cdot \mathrm{K})$ & 170 & 65 & 120 & 17 \\
\hline Specific Heat Capacity $(\mathrm{J} / \mathrm{kg} \cdot \mathrm{K})$ & 1050 & 500 & 390 & 510 \\
\hline Thickness $(\mathrm{mm})$ & 2 & 2 & 4 & 2 \\
\hline
\end{tabular}

A 2 phase-stepper motor with an IT 116 Flash controller, which actuates the axial movement. This controller has 128 micro steps for one full step by which a very smooth motion is possible for the connected 2 phase stepper motor. This movement is similar to the real DC casting process, where the ingot or billet is the moving part instead of the plate. The casting speed depends on the experimental requirements, which is completely controlled by the motor.

In case of a stationary mold setup, the mold is kept fixed at the top of hot metal sheet. The cooling water was delivered by a centrifugal pump from the top of the mold and flow out through the array of orifices which produce water jets. These jets impinge on the quenching side of the metal sample. It was ensured that the same amount of water flowed through every orifice. 


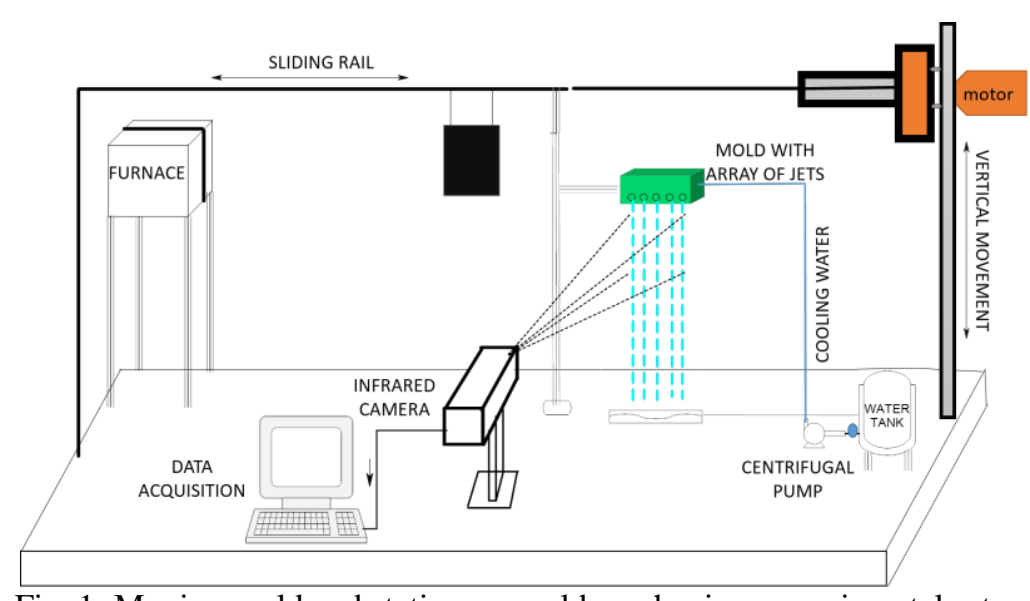

Fig. 1: Moving mold and stationary mold mechanism experimental setup.

\subsection{Experimental Sample}

A rectangular metal sheets with length and width as $250 \mathrm{~mm}$ and $90 \mathrm{~mm}$ respectively are used for experimental investigation. The samples were painted black on the measuring side in order to increase the emissivity, for a more accurate measurement. From the emissivity calibration process, it was found that the emissivity of the coating was stable in the range of 0.90 to 0.92 and independent from surface temperature.

For the purpose of accuracy, the thermal images were captured and stored at an extremely high frame rate of 150 images per second with the resolution of $240 \times 80$ pixels. Therefore, a temperature analysis can be done for every $0.84 \mathrm{~mm}$ and to an accuracy of $\pm 0.1 \mathrm{~K}$. The temperature measurement range of $100-500^{\circ} \mathrm{C}$ was used for this experimental setup. The results along the center line are considered for analysis in order to minimize the errors because of end effects.

Fig. 2 shows an example of thermal image from the infrared camera during the quenching process in moving mold. This acquired thermal history data was processed further in order to obtain the temperature data as a function of time and position.

\section{Analysis Method}

A model to obtain the heat flux as a function of temperature on the quenching side is developed by author. In this model the cooling because of discussion of heat is considered to identify the region where there is heat transfer with water. In this model the heat flux is obtained from a 1-D energy balance equation and is applied to a 2-D FD model as boundary condition to obtain the temperature on the quenching side of metal sheet. The model is further discussed in other publications by the authors in Kulkarni et al. (2017) [14].

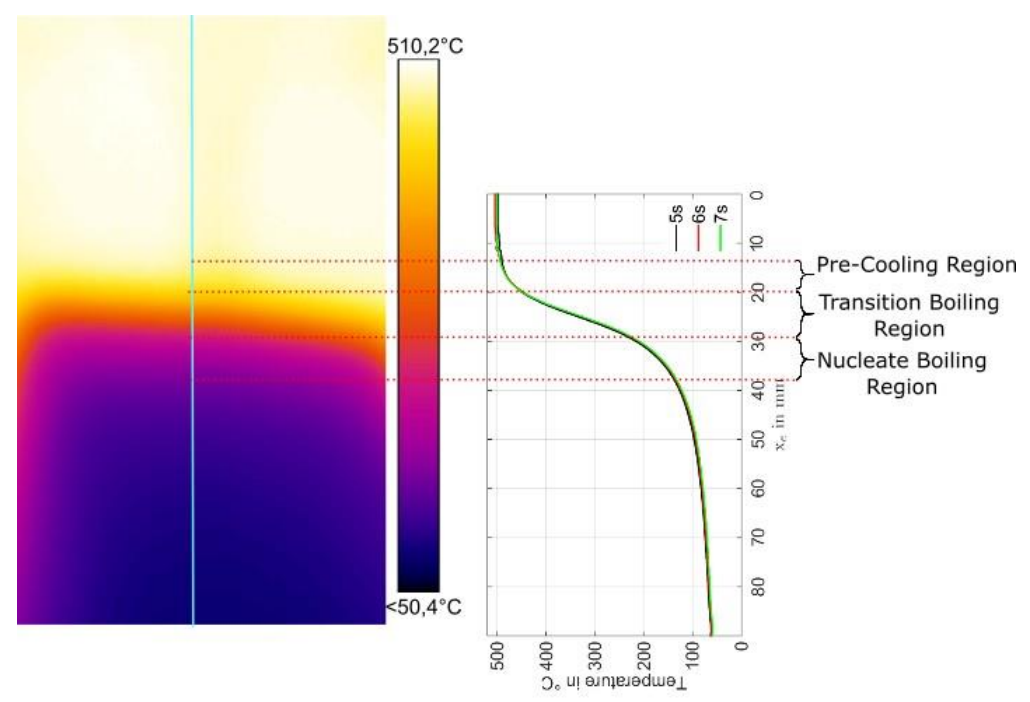

Fig. 2: Temperature profiles of metal sheet along the center line for Aluminum with $\mathrm{v}_{\mathrm{c}}=20 \mathrm{mmps}$, moving mold setup. 


\section{Results}

The thermal history data obtained from the experiments conducted, along with the analysis model was analysed for various parameters. This study was conducted to identify the parameters influencing the heat flux and the respective temperatures. Since, an infrared camera is used to measure the temperature, a full field temperature data is generated. These experimental temperature profiles along with the interface temperatures, can be superimposed on each other in order to provide us a preliminary idea of the trend cooling curves that can be expected from the raw experimental data. This data is processed further to obtain the boiling curves and the temperature profile on the quenching side of the metal sheet.

This temperature profile on the quenching side is used to analyse the widths of various wetting front regions. Firstly, a pre-cooling region, this is a region where cooling occurs because of heat transfer in the axial direction to the cool region. The start of this region can be considered when the temperature reaches $99 \%$ of initial temperature i.e. $T_{s}=99 \%$ of $T_{0}$ on the quenching side. The end of this region can be considered when the temperature on the quenching side reaches the interface temperature $\mathrm{T}_{\mathrm{z}=0}$.

Secondly, transition boiling region, this is the region where the heat flux to quenching water increases with cooling of the metal sheet. In this region the heat flux is because of partial contact between quenching water and hot metal sheet. The start of this region can be considered when the temperature on the quenching side is interface temperature $T_{z=0}$ and the end will be when the heat flux reaches maximum at DNB temperature $\mathrm{T}_{\mathrm{DNB}}$.

Thirdly, nucleate boiling region, this is the region where heat flux decreases with cooling of metal sheet. Physically this region can be identified by intensive bubble formation on the surface of metal sheet. The start of this region can be considered when the temperature on the quenching side is $\mathrm{DNB}$ temperature $\mathrm{T}_{\mathrm{DNB}}$ and the end can be considered when the temperature reaches $100^{\circ} \mathrm{C}$.

In the moving sheet setup the water contact is initially at the bottom of the hot metal sheet and starts moving to the top with a specified speed and in the stationary sheet setup the initial contact is at the top of metal sheet and the wetting front moves down. In the steady state region the velocity of the wetting front will be same as the sheet movement speed in moving sheet setup and in stationary setup the wetting front velocity id determined by tracking the minimum of second temperature derivative. The wetting front will be preceded by a pre-cooling region where temperature drop will be because of diffusion of heat in the cooler quenching region. The wet region will be divided into transition boiling region, Nucleate boiling region and cooling because of forced convection. The cooling because of forced convection is well established as the Nusselt number can be determined to obtain heat flux consecutively. The Transition and Nucleate boiling region will have high horizontal momentum like the cooling in the impingement zone. Various parameters like casting speed, types of metals and initial temperature of metals are analysed in this section.

\subsection{Different Casting Speeds}

In order to quantify the influence of casting speed on the cooling of a metal sheet, a 5mm thick aluminum AA6082 sheet was used. This sheet was heated to a temperature of nearly $500^{\circ} \mathrm{C}$ and was quenched with tap water at $22{ }^{\circ} \mathrm{C}$ jet velocity of $3.0 \mathrm{~mm} / \mathrm{s}$, and was quenched with different moving speeds and the superim- posed temperature profiles Fig. 3a, boiling curves Fig. $3 \mathrm{~b}$ and front widths Tab. 2 were analysed. It can be observed that with increase in casting speeds, the interface temperature increases along with the maximum heat flux. The width of pre-cooling region decreases with increasing casting velocities.

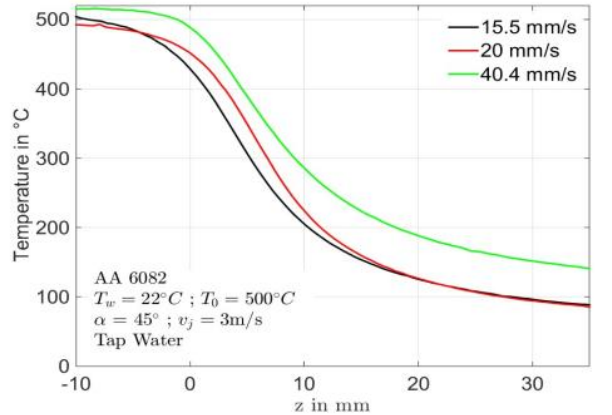

(a) Temperature profiles superimposed

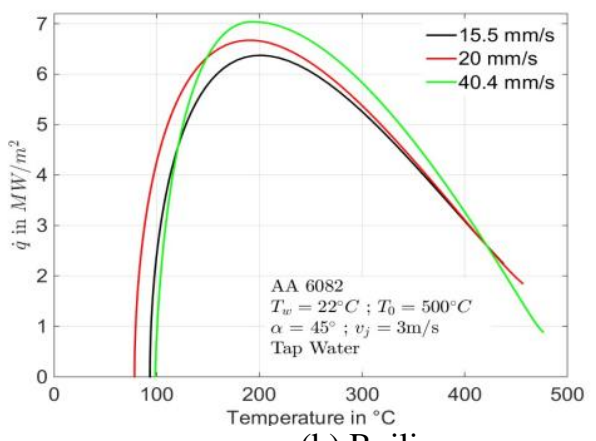

(b) Boiling curve

Fig. 3: Different casting speeds. 


\subsection{Different Metals}

To identify how the heat transfer during quenching changes for different metals, experiments were conducted with Aluminum, Nickel and Nicrofer. These metals were selected because of there diverse material properties. These sheet were heated to a temperature of nearly $500^{\circ} \mathrm{C}$ and were quenched with mold moving speed on $20 \mathrm{~mm} / \mathrm{s}$ and the superimposed temperature profiles Fig. 4a, boiling curves Fig. $4 \mathrm{~b}$ and front widths Tab. 3 was analysed. It can be observed that the decrease in temperature in pre-cooling region is small in case of Nicrofer because of low thermal conductivity compared to Nickel and Aluminum.

Table 2: Front width for different casting speeds.

\begin{tabular}{|c|c|c|r|}
\hline & $15.5 \mathrm{~mm} / \mathrm{s}$ & $20 \mathrm{~mm} / \mathrm{s}$ & $40.4 \mathrm{~mm} / \mathrm{s}$ \\
\hline Pre-cooling Region & $10.73 \mathrm{~mm}$ & $6-89 \mathrm{~mm}$ & $3.48 \mathrm{~mm}$ \\
\hline Transition Boiling Region & $7.95 \mathrm{~mm}$ & $11.07 \mathrm{~mm}$ & $23.72 \mathrm{~mm}$ \\
\hline Nucleate Boiling Region & $9.01 \mathrm{~mm}$ & $7.28 \mathrm{~mm}$ & $>25 \mathrm{~mm} \mathrm{~T}_{\mathrm{s}}$ \\
\hline \hline$=0.99 * \mathrm{~T}_{0}$ & $506.2^{\circ} \mathrm{C}$ & $489.9^{\circ} \mathrm{C}$ & $509.3^{\circ} \mathrm{C}$ \\
\hline $\mathrm{T}_{\mathrm{z}=0}$ & $426{ }^{\circ} \mathrm{C}$ & $449.8^{\circ} \mathrm{C}$ & $485.1^{\circ} \mathrm{C}$ \\
\hline $\mathrm{T}_{\mathrm{dnb}}$ & $201.7^{\circ} \mathrm{C}$ & $194.7^{\circ} \mathrm{C}$ & $192.6^{\circ} \mathrm{C}$ \\
\hline
\end{tabular}

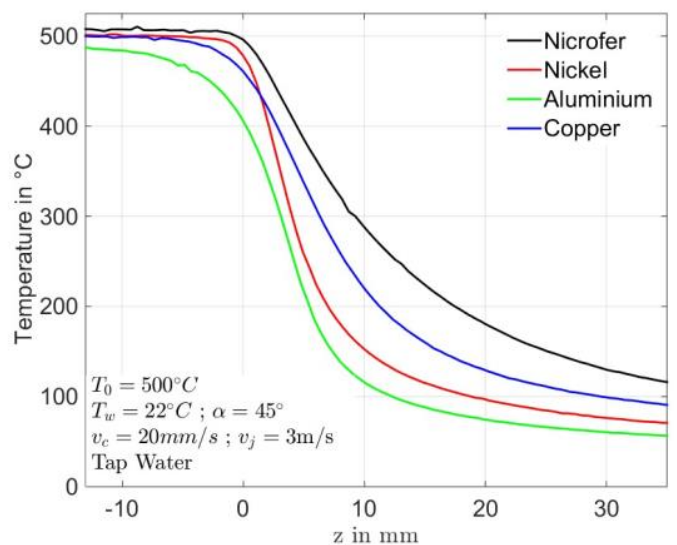

(a) Temperature profiles superimposed

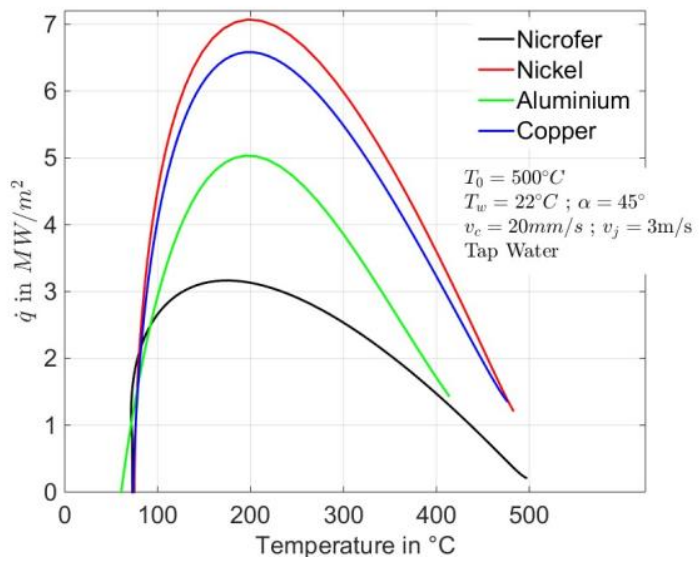

(b) Boiling curve

Fig. 4: Different Metals.

\subsection{Different Initial Temperatures}

Initial temperature is also thought to have an influence on heat flux during quenching of metal sheet. To quantify this influence, experiments were conducted on a $5 \mathrm{~mm}$ thick aluminium AA6082 sheet with casting speed of 20mm/s with tap water at $22{ }^{\circ} \mathrm{C}$ and jet velocity of $3 \mathrm{~m} / \mathrm{s}$. The superimposed temperature profiles Fig. 5a, boiling curves Fig. $5 \mathrm{~b}$ and front widths Tab. 4 were analysed. It can be seen that the boiling curve is different for different initial temperatures.

\subsection{Stationary Mold Setup}

In this setup the mold is places at the top of hot metal sheet and both the metal sheet and the mold remain fixed throughout the experiment. The initial flow of water is blocked with a metal barrier such that the jets will have a steady flow while impinging on the hot metal sheet, once removed. In this setup the wetting front will collapse at the top and will move downwards with time. This creates a cold wet region at the top and the water is ejected at the bottom region creating a hot dry region. A steady state will be achieved in mid region of the plate, where there is large enough cold wet region on the top and hot dry region at the bottom. The velocity of the wetting front can be determined from the experimental results by tracking the position of material at the interface temperature. It is observed that the wetting front velocity will remain constant in the steady state region. The wetting front will have pre-cooling region bellow in the dry region. In the wet region there 
will be cooling because of forced convection at the top followed be Nucleate boiling region and Transition boiling region. In the case of stationary mold setup the water curtain does not have significant horizontal momentum. Because of which formation of water vapours ejects the water curtain away from the hot plate. Hence the heat flux will be like the cooling in the free falling zone. Various parameters like jet velocity, kind of metal, initial temperature and temperature of cooling water are analysed.

Table 3: Front width for different metals.

\begin{tabular}{|c|c|c|c|r|}
\hline & Coppe & Aluminium & Nickel & Nicrofer \\
\hline Pre-cooling Region & $3.8 \mathrm{~mm}$ & $8.3 \mathrm{~mm}$ & $1.03 \mathrm{~mm}$ & $0.17 \mathrm{~mm}$ \\
\hline Transition Boiling Region & $11.9 \mathrm{~mm}$ & $5.54 \mathrm{~mm}$ & $7.96 \mathrm{~mm}$ & $22.06 \mathrm{~mm}$ \\
\hline Nucleate Boiling Region & $6.67 \mathrm{~mm}$ & $4.15 \mathrm{~mm}$ & $3.81 \mathrm{~mm}$ & $4.85 \mathrm{~mm}$ \\
\hline \hline $\mathrm{Ts}=0.99^{*} \mathrm{~T}_{0}$ & $495^{\circ} \mathrm{C}$ & $495^{\circ} \mathrm{C}$ & $495^{\circ} \mathrm{C}$ & $495^{\circ} \mathrm{C}$ \\
\hline $\mathrm{T}_{\mathrm{z}=0}$ & $462.2^{\circ} \mathrm{C}$ & $407.4^{\circ} \mathrm{C}$ & $477.5^{\circ} \mathrm{C}$ & $493.1^{\circ} \mathrm{C}$ \\
\hline $\mathrm{T}_{\text {dnb }}$ & $198.2^{\circ} \mathrm{C}$ & $194.2^{\circ} \mathrm{C}$ & $97.1^{\circ} \mathrm{C}$ & $176^{\circ} \mathrm{C}$ \\
\hline
\end{tabular}

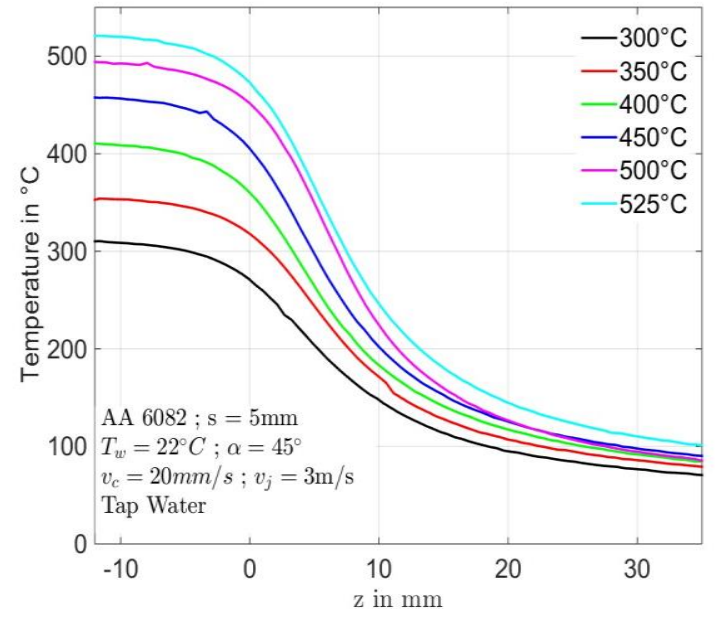

(a) Temperature profiles superimposed

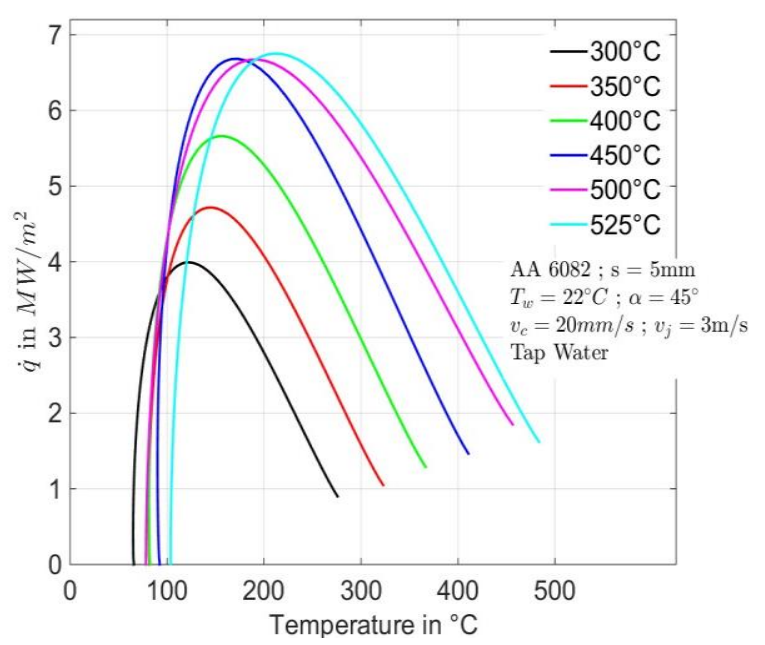

(b) Boiling curve

Fig. 5: Different Initial Temperatures.

Table 4: Front width for different initial temperatures.

\begin{tabular}{|c|c|c|c|c|c|c|}
\hline & $300{ }^{\circ} \mathrm{C}$ & $350^{\circ} \mathrm{C}$ & $400^{\circ} \mathrm{C}$ & $450^{\circ} \mathrm{C}$ & $500{ }^{\circ} \mathrm{C}$ & $525^{\circ} \mathrm{C}$ \\
\hline Pre-cooling Region & $5.9 \mathrm{~mm}$ & $5.53 \mathrm{~mm}$ & $5.88 \mathrm{~mm}$ & $5.88 \mathrm{~mm}$ & $5.88 \mathrm{~mm}$ & $5.88 \mathrm{~mm}$ \\
\hline Transition Boiling Region & $11.11 \mathrm{~mm}$ & $10.83 \mathrm{~mm}$ & $10.73 \mathrm{~mm}$ & $10.03 \mathrm{~mm}$ & $11.77 \mathrm{~mm}$ & $11.42 \mathrm{~mm}$ \\
\hline Nucleate Boiling Region & $2.1 \mathrm{~mm}$ & $4.15 \mathrm{~mm}$ & $4.5 \mathrm{~mm}$ & $5.89 \mathrm{~mm}$ & $6.93 \mathrm{~mm}$ & $>25 \mathrm{~mm}$ \\
\hline $\mathrm{Ts}=0.99^{*} \mathrm{~T}_{0}$ & $297^{\circ} \mathrm{C}$ & $346.5^{\circ} \mathrm{C}$ & $396^{\circ} \mathrm{C}$ & $445.5^{\circ} \mathrm{C}$ & $495^{\circ} \mathrm{C}$ & $519.8^{\circ} \mathrm{C}$ \\
\hline $\mathrm{T}_{\mathrm{z}=0}$ & $272.9^{\circ} \mathrm{C}$ & $317.1^{\circ} \mathrm{C}$ & $361.3^{\circ} \mathrm{C}$ & $405.4^{\circ} \mathrm{C}$ & $449.5^{\circ} \mathrm{C}$ & $472.9^{\circ} \mathrm{C}$ \\
\hline $\mathrm{T}_{\text {dnb }}$ & $123^{\circ} \mathrm{C}$ & $146.3^{\circ} \mathrm{C}$ & $153.5^{\circ} \mathrm{C}$ & $173.1^{\circ} \mathrm{C}$ & $188^{\circ} \mathrm{C}$ & $210.6^{\circ} \mathrm{C}$ \\
\hline
\end{tabular}

\subsection{Different Metal}

In order to quantify the influence the kind of metal has on the boiling curve, experiments were conducted on various metal sheets like Aluminum, Coper, Nicrofer and Nickel. The initial temperature was kept constant at 
$500^{\circ} \mathrm{C}$ and a fixed jet velocity of $3.0 \mathrm{~m} / \mathrm{s}$ and angle of $45^{\circ}$ was used for all the experiments. The superimposed temperature profile are shown in Fig: 6a, the obtained boiling curves are shown in Fig: 6b and the font widths are shown in Tab: 5. The superimposed temperature profiles for quenching of these different metals is as depicted in Fig: 6a. It can be seen that the temperature gradient for Aluminium is highest and is less in case of Nicrofer. From the boiling curves it can be seen that the maximum heat flux for Aluminium is highest. Because of low thermal conductivity of Nicrofer, the width of pre-cooling region for Nicrofer is small and the transition boiling region and nucleate boiling region is high. In case of Aluminum the width transition boiling region is higher and the nucleate boiling region is lower than Coper.

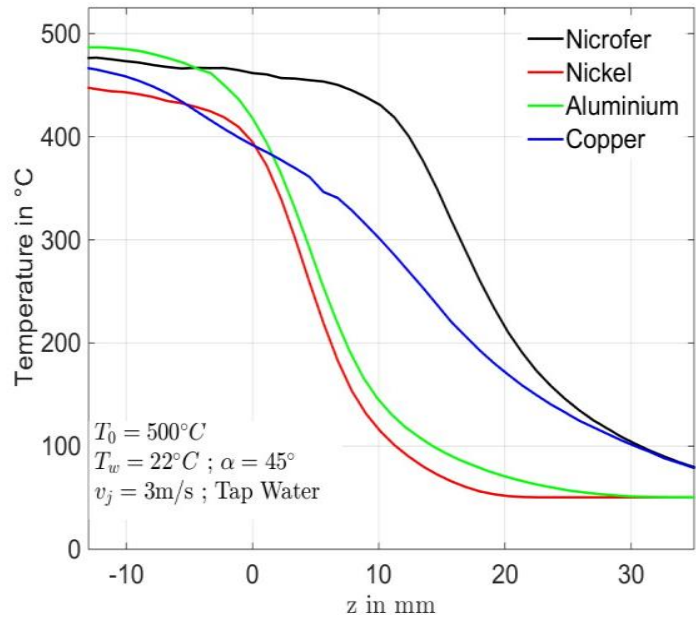

(a) Temperature profiles superimposed

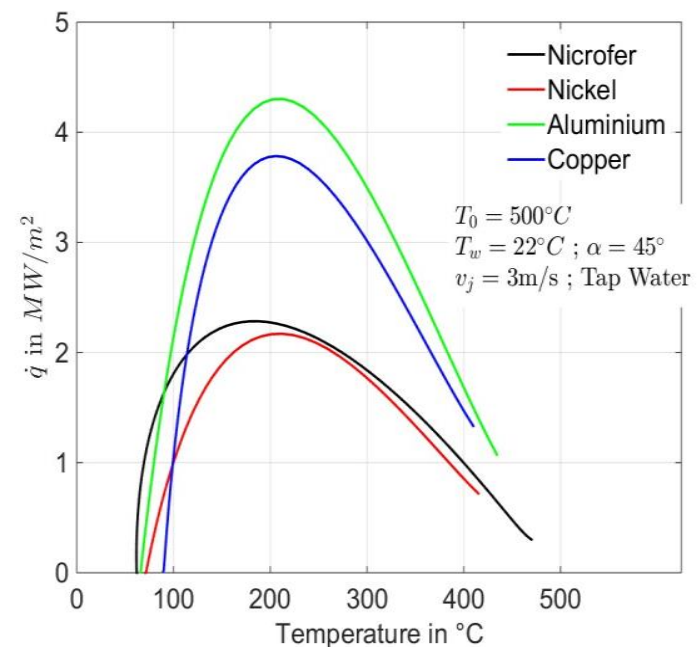

(b) Boiling curve

Fig. 6: Different metals for stationary mold setup.

Table 5: Front width for different metals for stationary mold setup.

\begin{tabular}{|c|c|c|c|c|}
\hline & Copper & Aluminium & Nickel & Nicrofer \\
\hline Pre-cooling Region & $14.4 \mathrm{~mm}$ & $8.6 \mathrm{~mm}$ & $6.63 \mathrm{~mm}$ & $1.24 \mathrm{~mm}$ \\
\hline Transition Boiling Region & $7.35 \mathrm{~mm}$ & $6.81 \mathrm{~mm}$ & $5.54 \mathrm{~mm}$ & $14.17 \mathrm{~mm}$ \\
\hline Nucleate Boiling Region & $10.47 \mathrm{~mm}$ & $6.09 \mathrm{~mm}$ & $5.94 \mathrm{~mm}$ & $4.66 \mathrm{~mm}$ \\
\hline Wetting front velocity & $9.86 \mathrm{~mm} / \mathrm{s}$ & $21.49 \mathrm{~mm} / \mathrm{s}$ & $7.07 \mathrm{~mm} / \mathrm{s}$ & $11.71 \mathrm{~mm} / \mathrm{s}$ \\
\hline $\mathrm{Ts}=0.99^{*} \mathrm{~T}_{0}$ & $495^{\circ} \mathrm{C}$ & $485^{\circ} \mathrm{C}$ & $460.35^{\circ} \mathrm{C}$ & $475^{\circ} \mathrm{C} \mathrm{T}_{z}=0$ \\
\hline $395.35^{\circ} \mathrm{C}$ & $.6^{\circ} \mathrm{C}$ & $18^{\circ} \mathrm{C}$ & $11^{\circ} \mathrm{C} \mathrm{T}_{d n b}$ & \\
\hline $205.7^{\circ} \mathrm{C}$ & $7^{\circ} \mathrm{C}$ & 187.8 & ${ }^{\circ} \mathrm{C}$ & \\
\hline
\end{tabular}

\subsection{Different Initial Temperature}

The initial temperature of the metal sheet is also expected to have an influence on the cooling characteristics during experiments with stationary mechanism. With changing the initial temperature of the metal sheet, the heat capacity of the system changes. Because of this it can be imagined that the heat transfer character will change. For this reason, experiments were conducted on a $5 \mathrm{~mm}$ thick AA6082 sheet quenching with tap water at $22{ }^{\circ} \mathrm{C}$ with a jet angle of $45^{\circ}$ and jet velocity of $3 \mathrm{~m} / \mathrm{s}$. The initial temperature of the metal sheet is changed in range of $300{ }^{\circ} \mathrm{C}$ to $525{ }^{\circ} \mathrm{C}$. The superimposed temperature profiles during quenching of AA6082 sheet with different initial temperature are depicted in Fig:7a. From this figure it can be observed that the wetting temperature changes with the initial temperature. Fig: 7b shows the boiling curves for different initial temperature. From this figure it can be observed that the maximum heat flux and DNB temperature strongly depends on the initial temperature. 


\section{Conclusion}

A model which takes into account the temperature difference on quenching side and measuring side of the metal sheet along with the pre-cooling caused by diffusion is used to obtain the boiling curve in the steady state region under a moving mold condition and a stationary mold condition. Various experiments were conducted to identify the influencing parameters.

It can be observed that metals with high thermal conductivity, have a longer pre-cooling region and this region is even longer when the casting speed is lower. In metal casting and processing industry, it is required that the cooling rate should be greater than critical cooling rate in order to obtain good material properties.

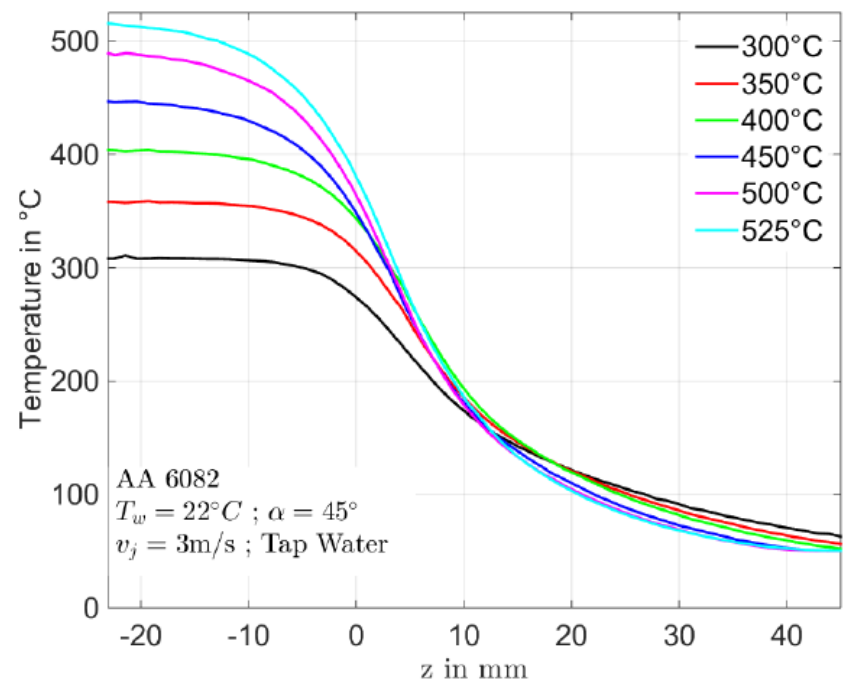

(a) Temperature profiles superimposed

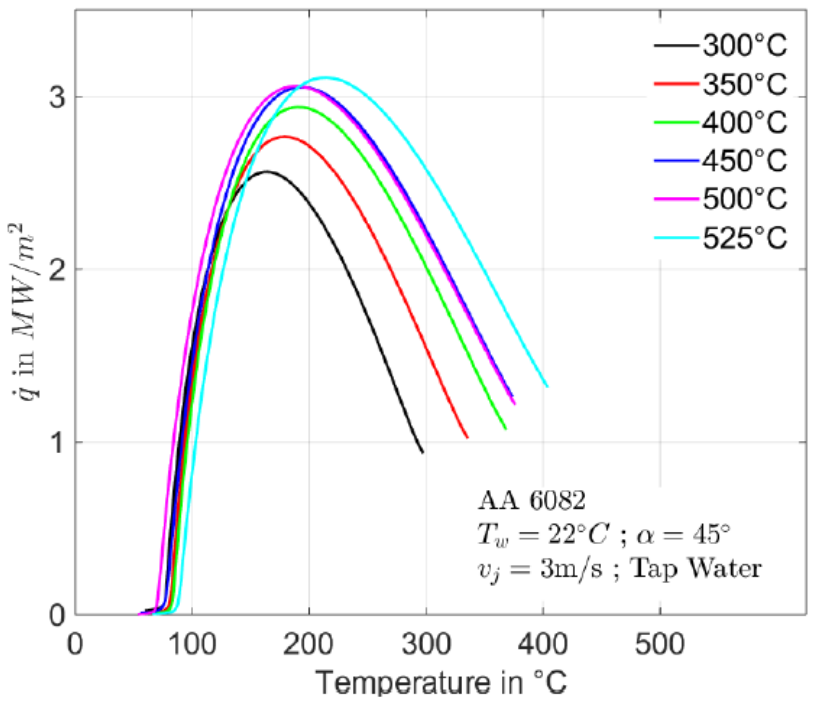

(b) Boiling curve

Fig. 7: Different jet velocities for stationary mold setup.

Table 6: Front width for different initial temperature for stationary mold setup.

\begin{tabular}{|c|r|r|r|r|r|r|}
\hline & $300{ }^{\circ} \mathrm{C}$ & $350{ }^{\circ} \mathrm{C}$ & $400{ }^{\circ} \mathrm{C}$ & $450{ }^{\circ} \mathrm{C}$ & \multicolumn{1}{|c|}{$500{ }^{\circ} \mathrm{C}$} & $525^{\circ} \mathrm{C}$ \\
\hline Pre-cooling Region & $6.63 \mathrm{~mm}$ & $8.96 \mathrm{~mm}$ & $11.83 \mathrm{~mm}$ & $17.21 \mathrm{~mm}$ & $19.72 \mathrm{~mm}$ & $19.36 \mathrm{~mm}$ \\
\hline Transition Boiling Region & $13.8 \mathrm{~mm}$ & $11.47 \mathrm{~mm}$ & $10.39 \mathrm{~mm}$ & $8.60 \mathrm{~mm}$ & $8.24 \mathrm{~mm}$ & $8.24 \mathrm{~mm}$ \\
\hline Nucleate Boiling Region & $11.11 \mathrm{~mm}$ & $12.19 \mathrm{~mm}$ & $12.19 \mathrm{~mm}$ & $10.04 \mathrm{~mm}$ & $8.25 \mathrm{~mm}$ & $14.34 \mathrm{~mm}$ \\
\hline \hline Wetting Front Velocity & $21.75 \mathrm{~mm} / \mathrm{s}$ & $16.63 \mathrm{~mm} / \mathrm{s}$ & $12.84 \mathrm{~mm} / \mathrm{s}$ & $9.24 \mathrm{~mm} / \mathrm{s}$ & $9.17 \mathrm{~mm} / \mathrm{s}$ & $9.42 \mathrm{~mm} / \mathrm{s}$ \\
\hline $\mathrm{Ts}_{=} 0.99 * \mathrm{~T}_{0}$ & $310{ }^{\circ} \mathrm{C}$ & $360.36{ }^{\circ} \mathrm{C}$ & $412.24{ }^{\circ} \mathrm{C}$ & $461{ }^{\circ} \mathrm{C}$ & $482.82{ }^{\circ} \mathrm{C}$ & $511.83{ }^{\circ} \mathrm{C}$ \\
\hline $\mathrm{T}_{z=0}$ & $276.41{ }^{\circ} \mathrm{C}$ & $311.62{ }^{\circ} \mathrm{C}$ & $343{ }^{\circ} \mathrm{C}$ & $354{ }^{\circ} \mathrm{C}$ & $361.87{ }^{\circ} \mathrm{C}$ & $386.9{ }^{\circ} \mathrm{C}$ \\
\hline $\mathrm{T}_{\text {dnh }}$ & $161.8{ }^{\circ} \mathrm{C}$ & $179{ }^{\circ} \mathrm{C}$ & $190.02{ }^{\circ} \mathrm{C}$ & $190.02{ }^{\circ} \mathrm{C}$ & $190.01{ }^{\circ} \mathrm{C}$ & $215.5^{\circ} \mathrm{C}$ \\
\hline
\end{tabular}

With the obtained results it can be concluded that a higher metal sheet moving speed should be maintained in order to minimize the slow cooling in the pre-cooling region. Though this increases the length of the quenching setup, the pre-cooling region can be minimized. Also it should be noted that the high cooling rate increases the thermal gradients in metal increasing the thermal stresses. This might lead to failure in the metal and hence an optimized cooling rate should be determined and used. 
DNB temperature or the temperature where the heat flux is maximum is in the range of nearly $190^{\circ} \mathrm{C}-210^{\circ} \mathrm{C}$ for an initial temperature of $500^{\circ} \mathrm{C}$, under a moving sheet condition despite of various casting speeds and different kinds of metals. This phenomenon has been observed and published by many authors. For higher initial temperature, the DNB temperature also is higher. It can be observed that the maximum heat flux, decreases for decreasing casting velocity. Nickel demonstrates a higher maximum heat flux in moving sheet setup where as in stationary setup, the behavior is contrary. It can also be observed that the initial temperature also has a strong influence on the maximum heat flux for a metal sheet. This could also explain the difference in maximum heat flux for different casting speeds as the temperature at which metal sheet will experience water cooling will vary.

The maximum heat flux is lesser in case of stationary mold compared to the moving sheet setup. This is also expected as the heat flux in moving sheet setup will depict boiling curve in the impingement zone and that in stationary setup depicts in free falling zone. This is also because the flow in impingement zone is turbulent, defusing the bubbles from the hot metal sheet.

\section{Acknowledgements}

The authors also acknowledge the financial support provided by the Graaduiertenkolleg-1554 (GKMM) through the German Research Foundation (DFG).

\section{References}

[1] E. Elias, and G. Yadigarogul, "A General one-dimensional Model for Conduction-Controled Rewetting of a Sur- face," Nuclear Engineering and Design, vol. 42, no. 2, pp. 185-194, 1977.

[2] M. A. Wells, and D. Li, and S. L. Cockcroft, "Influence of Surface Morphology, water flow rate and sample thermal history on the boiling-water heat transfer during Direct-chill casting of commercial aluminum alloys," Metallurgical and Materials Transactions B, vol. 32B, pp. 929-939, 2001.

[3] A. K. Nallathambi, and E. Specht, "Estimation of heat flux in array of jets quenching using experimental and inverse finite element method," Journal of Materials Processing Technology, vol. 209, pp. 5325-5332, 2009.

[4] A. K. Mozumder, and M. Monde, and P. L. Woodfield, "Delay of wetting propagation during jet impingement quenching for a high temperature surface," International Journal of Heat and Mass Transfer, vol. 48, pp. 5395-5407, 2005.

[5] M. Akmal, and A. M. T. Omar, and M. S. Hamed, "Experimental investigation of propagation of wetting front on curved surfaces exposed to an impinging water jet," International Journal of Microstructure and Materials Properties, vol. 3, pp. 645-681, 2008.

[6] J. A. Bakken and T. Bergstrm, "Heat Transfer Measurments during DC casting of Aluminum," Light Metals, pp. 646$652,1986$.

[7] I. J. Opstelten, and J. M. Rabenberg, "Determination of the thermal boundary conditions during aluminum DC casting from experimental data using inverse modeling," Light Metals, pp. 665-671, 1999.

[8] M. Hnizdil, M. Chabicovsky, and M. Raudensky, "Influence of the impact angle and pressure on spray cooling of vertically moving hot steel surfaces," Materials and Technology, vol. 49, pp. 333-336, 2015.

[9] J. -V. C. Beck, B. Blackwell, and C. -R. St-Clair, "Inverse Heat Conduction - Ill-Posed Problems," Wiley, New York, 1985.

[10] U. Z. Ijaz, A. K. Khambampati, M. C. Kim, S. Kim, and K. Y. Kim, "Estimation of time-dependent heat flux and measurement bias in two-dimensional inverse heat conduction problems," International Journal of Heat and Mass Transfer, vol. 50, pp. 4117-4130, 2007.

[11] C. H. Huang, and H. H. Wu, "An inverse hyperbolic heat conduction problem in estimating surface heat flux by conjugate gradient method," Journal of Physics D-Applied Physics, vol. 39, pp. 4087-4096, 2006.

[12] S. Deng, and Y. Hwang, "Applying neural networks to the solution of forward and inverse heat conduction problems," International Journal of Heat and Mass Transfer, vol. 42, pp. 4732-4750, 2006.

[13] M. Gradeck, J. A. Quattara, B. Re'my, and D. Maillet, "Solution of an inverse problem in the Hankel space Infrared thermography applied to estimation of a transient cooling flux," Experimental Thermal and Fluid Science, vol. 36, 2012, pp. 56-64. 
[14] G. A. Kulkarni, and Sabariman and E. Specht, "Jet Impingement Heat Transfer of Moving Metal Sheet Heat Transfer," Fluid Mechanics and Thermodynamics, pp. 393-400, 2017. ISBN: 978-1-77592-140-0.

[15] M. K. Agrawal, S. K. Sahu, "Analysis of conduction-controlled rewetting of a hot surface by variational method," Heat Mass Transfer, vol. 49, pp. 963-971, 2013.

[16] A. Yamanouchi, "Effect of Core Spray Cooling in Transient State after Loss of Coolant Accident," Journal of Nuclear Science and Technology, vol. 5, no. 11, pp. 547-558, 1968. 